\title{
ANALISA POSTUR KERJA DENGAN NORDIC BODY MAP \& REBA PADA TEKNISI PAINTING DI PT. JAKARTA TEKNOLOGI UTAMA MOTOR PEKANBARU
}

\author{
Denny Astrie Anggraini, Nico Ciri Bati \\ Program Studi Teknik Industri Fakultas Teknik Universitas Muhammadiyah Riau \\ Jalan Tuanku Tambusai Ujung (Samping SKA) Pekanbaru \\ e-mail: d_nny0204@yahoo.com¹, nicociribati@gmail.com²
}

\begin{abstract}
ABSTRAK
PT. Jakarta Teknologi Utama Motor Pekanbaru adalah perusahaan perbaikan body kendaraan. Dalam pelaksanaan pekerjaannya terdapat keluhan yang dirasakan teknisi khususnya bagian painting, yaitu keluhan rasa sakit pada punggung dan bagian tubuh lain yang disebabkan oleh kesalahan postur kerja atau ketidak ergonomisan fasilitas kerja yang dapat mempengaruhi kondisi kesehatan, produktivitas serta kualitas hasil kerja. Berdasarkan penilaian dengan metode REBA (Rapid Entire Body Assesment) menunjukkan bahwa aktivitas pengecatan (a) termasuk kategori high risk artinya perlu perbaikan segera. Aktivitas pengamplasan (b) termasuk kategori very high risk artinya perlu perbaikan sekarang. Sedangkan aktivitas pendempulan (c) termasuk dalam kategori medium risk yang berarti diperlukan perbaikan pada postur ini. Rekomendasi yang diberikan agar dapat mengurangi resiko cedera pada teknisi yaitu perlu ada perbaikan posisi kerja dan penambahan peralatan kerja.
\end{abstract}

Kata kunci: Postur Kerja, Keluhan, REBA

\section{PENDAHULUAN}

Produktivitas kerja adalah kemampuan pekerja dalam berproduksi dibandingkan dengan input yang digunakan, seorang pekerja dapat dikatakan produktif apabila mampu menghasilkan barang atau jasa sesuai dengan yang diharapkan. Di dalam proses produksi, produktivitas ditopang oleh tiga pilar yaitu Kuantitas (Quantity), Kualitas (Quality) dan Keselamatan (Safety), apabila salah satu tidak tercapai maka produktivitas juga tidak akan tercapai. Keselamatan pekerja ini harus diperhatikan karena menyangkut manusia sebagai pemegang peranan penting dalam proses produksi. Sebagai salah satu yang terlibat dalam proses produksi, pekerja memegang peranan sangat penting. Ketika seorang pekerja melakukan kerja secara berlebihan akan mengakibatkan terjadinya human error atau bahkan kecelakaan kerja yang dapat menurunkan produktivitas.

PT. Jakarta Teknologi Utama Motor Pekanbaru memperbaiki kendaraan yang mengalami kerusakan pada bagian bodi (body repair specialist). Kegiatan perbaikan yang dilakukan meliputi beberapa tahapan sesuai dengan tingkat kerusakan kendaraan. Tahapan tersebut dimulai dari pengetokan hingga pengecatan dan akhirnya dapat memulihkan kondisi kendaraan pelanggan.

Terkhusus untuk aktivitas-aktivitas pekerjaan divisi painting secara umum berkaitan dengan pendempulan, pengamplasan dan juga pengecatan permukaan bodi kendaraan. Pendempulan adalah aktivitas memulihkan bentuk permukaan dengan memberikan bahan berupa dempul (Putty) dengan bantuan alat yang biasa disebut kape atau spatula. Pengamplasan adalah aktivitas menghaluskan permukaan panel kendaraan dengan cara menggosokkan lembaran amplas secara manual. Amplas yang di gunakan disesuaikan dengan grid amplas dan kondisi permukaan. Pengecatan adalah aktivitas memberikan identifikasi warna pada permukaan bodi mobil sesuai dengan warna semula. Alat yang digunakan untuk menyemprotkan cat disebut spraygun Pengecatan dilakukan di dalam ruangan khusus yang biasa disebut spraybooth. 


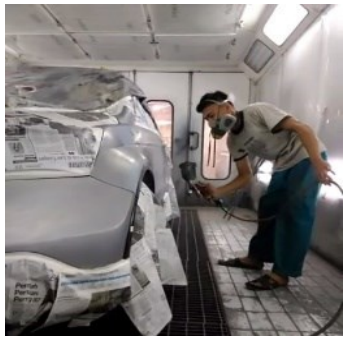

(a) Pengecatan

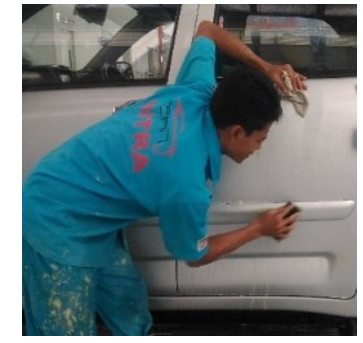

(b) Pegamplasan
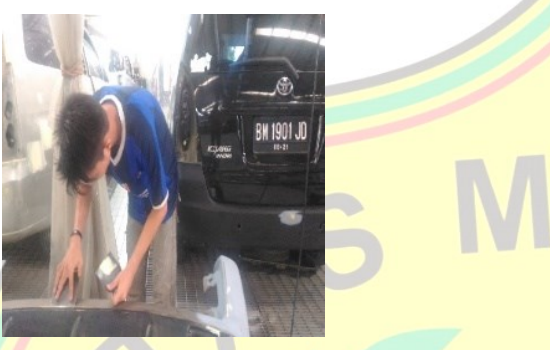

(c) Pendempulan

\section{Gambar 1. Aktivitas Pekerjaan Bagian Painting}

Aktivitas-aktivitas tersebut dilakukan terus menerus dan berulang-ulang selama bekerja, banyaknya unit kendaraan yang perlu perbaikan menunjukkan durasi kerja yang tinggi pula. Hal ini menyebabkan durasi teknisi terpapar bahaya di tempat kerja juga semakin tinggi. Selain itu, peralatan kerja dan postur kerja dinilai tidak ergonomis.

Hal ini dapat dilihat dari adanya keluhan teknisi yaitu rasa nyeri di bagian tubuh tertentu. Apabila postur kerja yang buruk tersebut dibiarkan begitu saja akan berdampak terhadap kesehatan tubuh teknisi dan produktivitas yang dihasilkan. Oleh karena itu, diperlukan suatu evaluasi yang berkaitan dengan resiko ergonomi agar dapat mengurangi keluhan teknisi yang menghambat produktivitas di PT. Jakarta Teknologi Utama Motor Pekanbaru.

Pada Penelitian ini, peneliti fokus untuk mengukur resiko ergonomi pada divisi painting dengan menggunakan metode Rapid Entire Body Assesment (REBA). Metode ini bertujuan untuk mengetahui resiko ergonomi terutama keluhan otot skeletal dan resiko bahaya yang di terima teknisi painting.

Berikut adalah tabel rekapitulasi kuesioner Nordic Body Map berdasarkan pengelompokan jenis keluhan:
Tabel 1. Rekapitulasi Kuesioner Nordic Body Map Berdasarkan Pengelompokan Jenis

Keluhan

\begin{tabular}{|l|c|}
\hline \multicolumn{1}{|c|}{ Kategori } & Jenis Keluhan \\
\hline Tidak sakit & $9,10,13,17,21,24,26,27$ \\
\hline Agak sakit & $0,2,4,6,11,12,14,16,18,19,20,22,23,25$ \\
\hline Sakit & $1,3,5,7,8,15$ \\
\hline Sangat sakit & tidak ada \\
\hline
\end{tabular}

\section{Metode Analisa Postur Kerja}

REBA atau Rapid Entire Body Assessment dikembangkan oleh Dr. Sue Hignett dan Dr. Lynn Mc Atamney yang merupakan ergonom dari universitas di Nottingham (University of Nottingham's Institute of OccuPT.aional Ergonomic). Rapid Entire Body Assessment adalah sebuah metode yang dikembangkan dalam bidang ergonomi dan dapat digunakan secara cepat untuk menilai posisi kerja atau postur leher, punggung, lengan pergelangan tangan dan kaki seorang pekerja .Selain itu metode ini juga dipengaruhi faktor coupling, beban eksternal yang ditopang oleh tubuh serta aktivitas pekerja. Penilaian dengan menggunakan REBA tidak membutuhkan waktu yang lama untuk melengkapi dan melakukan scoring general pada daftar aktivitas yang mengindikasikan perlu adanya pengurangan resiko yang diakibatkan postur kerja pekerja (Mc Atamney, 2000).

\section{Nordic Body Map}

Nordic Body Map digunakan untuk mengetahui keluhan musculosceletal disorder (MSDs) yang dirasakan pekerja. Keluhan MSDs tersebut akan diketahui dengan menggunakan kuesioner yang berupa beberapa jenis keluhan MSDs pada peta tubuh manusia. Melalui kuesioner ini dapat diketahui bagian otot yang mengalami keluhan dengan tingkat keluhan mulai dari Tidak Sakit (A), Agak Sakit (B), Sakit (C) dan Sangat Sakit (D). 


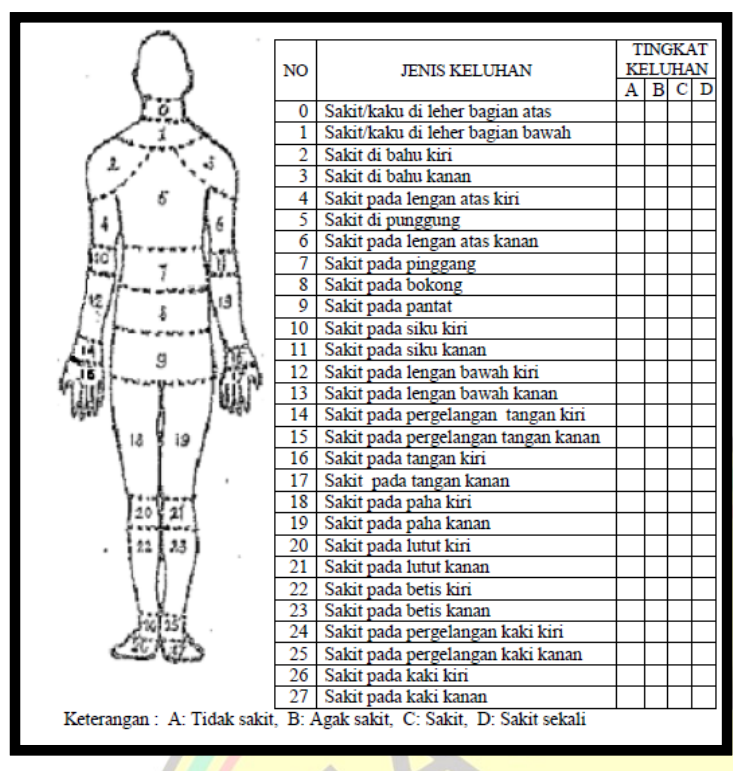

Gambar 2. Kuesioner Nordic Body Map Sumber: Santoso, 2004

\section{Penelitian} in

bertujuan untuk mengidentifikasi keluhan yang dirasakan teknisi painting dengan menggunakan Nordic Body Map, melakukan penilaian ergonomi (ergonomic assesment) menggunakan metode REBA terhadap risiko keluhan otot skeletal dan risiko bahaya pada teknisi bagian Painting di PT. Jakarta Teknologi Utama Motor Pekanbaru dan memberi rekomendasi perbaikan berdasarkan hasil penilaian ergonomi (ergonomic assesment) agar dapat diimplementasi pada teknisi dan perusahaan.

\section{METODOLOGI PENELITIAN}

Metodologi yang digunakan dalam penelitian ini terdiri dari beberapa tahap, yaitu :

- Tahap Studi Pendahuluan, meliputi :

1. Perumusan Masalah yang akan diteliti,

2. Tinjauan Pustaka dan Tinjauan Lapangan,

3. Perumusan Tujuan Penelitian.

- Tahap Identifikasi, meliputi :

1. Pemilihan Metode yang akan digunakan,

2. Penentuan Tempat Penelitian,

3. Penentuan Data yang dibutuhkan.

- Tahap Pengumpulan Data, meliputi :

1. Penentuan responden dan total responden,

2. Penyebaran Kuesioner Nordic Body map,

3. Pengambilan foto Postur kerja,
- Tahap Pengolahan dan Analisa data, meliputi :

1. Penggunaan REBA (Rapid Entire Body Assesment) untuk menilai posisi kerja,

2. Melakukan Pengelompokan bagian tubuh menjadi 2 yaitu A dan B.

3. Melakukan Perhitungan Skor sesuai dengan postur kerja teknisi untuk mengidentifikasi tindakan apa yang perlu dilakukan,

4. Menganalisis hasil pengolahan.

- Tahap Pengambilan Kesimpulan.

\section{HASIL DAN PEMBAHASAN}

Penilaian terhadap postur kerja dilakukan dengan menggunakan metode REBA (Rapid Entire Body Assessment). Metode ini mengevaluasi postur, kekuatan, aktivitas dan faktor coupling yang dapat menimbulkan cedera akibat aktivitas yang berulang-ulang. Penggunaan metode REBA pada studi kasus ini terjadi dalam dua tahap.

Tahap pertama adalah pengambilan data postur kerja dengan menggunakan dokumentasi foto teknisi saat akan melakukan 3 aktivitas produksi. Aktivitas ini dilakukan berulangulang oleh teknisi setiap kali produksi. Aktivitas (a) adalah aktivitas teknisi yang sedang melakukan pengecatan kendaraan mobil di dalam ruang spraybooth. Aktivitas (b) adalah aktivitas seorang teknisi yang sedang melakukan pengamplasan permukaan bodi mobil. Sedangkan aktivitas (c) adalah aktivitas teknisi yang sedang melakukan pendempulan pada mobil.

Tahap kedua adalah penentuan sudut-sudut dari bagian tubuh teknisi pada foto yang telah diambil serta penentuan berat benda yang diangkat, penentuan coupling dan penentuan resiko aktivitas teknisi.

Berikut ini merupakan penilaian postur tubuh pada teknisi yang meliputi ketiga aktivitas dalam proses produksi:

A. Analisa Bagian Leher, Punggung Dan Kaki

1. Step 1, Posisi Leher

Berikut klasifikasi skor untuk posisi leher yang akan disesuaikan dengan postur tubuh teknisi. 
Tabel 2. Klasifikasi Posisi Leher

\begin{tabular}{|l|r|l|}
\hline Posisi Leher & Skor & $\begin{array}{l}\text { Perubahan } \\
\text { Skor }\end{array}$ \\
\hline $0^{\circ}-20^{\circ}$ flexion & 1 & $\begin{array}{l}+1 \text { Jika memutar } \\
\text { /miring } \\
\text { kesamping }\end{array}$ \\
\hline $\begin{array}{l}>20^{\circ} \text { flexion atau } \\
\text { extension }\end{array}$ & 2 & \begin{tabular}{l} 
kion \\
\hline
\end{tabular}
\end{tabular}

Tabel 3. Pemberian Skor Posisi Leher

\begin{tabular}{|c|c|c|c|}
\hline Step 1 & $\begin{array}{c}\text { Aktivitas } \\
\text { (a) }\end{array}$ & $\begin{array}{c}\text { Aktivitas } \\
\text { (b) }\end{array}$ & $\begin{array}{c}\text { Aktivitas } \\
\text { (c) }\end{array}$ \\
\hline $\begin{array}{c}\text { Sudut } \\
\text { Posisi } \\
\text { Leher }\end{array}$ & $\begin{array}{c}> \\
\text { extension }\end{array}$ & $>20^{\circ}$ & $0^{\circ}-20^{\circ}$ \\
\hline Sktension & 2 & 2 & 1 \\
\hline
\end{tabular}

Posisi leher teknisi pada aktivitas (a) dan aktivitas (b) sama, yaitu 2. Sedangkan skor untuk aktivitas (c) adalah 1.

\section{Step 2, Posisi Punggung}

Setelah mengetahui sudut yang dibentuk dari posisi punggung teknisi, maka selanjutnya adalah memberi skor dengan klasifikasi sebagai berikut:

Tabel 4. Klasifikasi Posisi Punggung

\begin{tabular}{|c|c|c|}
\hline Posisi Punggung & Skor & $\begin{array}{c}\text { Perubahan } \\
\text { Skor }\end{array}$ \\
\hline Tegak/alamiah & 1 & \multirow{4}{*}{$\begin{array}{c}+1 \text { Jika } \\
\text { memutar } \\
\text { /miring ke } \\
\text { samping }\end{array}$} \\
\hline $\begin{array}{l}0^{\circ}-20^{\circ} \text { flexion } \\
0^{\circ}-20^{\circ} \text { extension }\end{array}$ & 2 & \\
\hline $\begin{array}{l}20^{\circ}-60^{\circ} \text { flexion } \\
>20^{\circ} \text { extension }\end{array}$ & 3 & \\
\hline$>60^{\circ}$ flexion & 4 & \\
\hline
\end{tabular}

Tabel 5. Pemberian Skor Posisi Punggung

\begin{tabular}{|l|c|c|c|}
\hline Step 2 & $\begin{array}{c}\text { Aktivitas } \\
\text { (a) }\end{array}$ & $\begin{array}{c}\text { Aktivitas } \\
\text { (b) }\end{array}$ & $\begin{array}{c}\text { Aktivitas } \\
\text { (c) }\end{array}$ \\
\hline $\begin{array}{l}\text { Sudut } \\
\text { Posisi } \\
\text { Punggung }\end{array}$ & $>60^{\circ}$ & $>60^{\circ}$ & $>60^{\circ}$ \\
$(+1)$ & \\
\hline Skor & 4 & 5 & 4 \\
\hline
\end{tabular}

Posisi punggung teknisi pada aktivitas (a), dan aktivitas (c) sama yaitu berada pada range $>60^{\circ}$, maka skor untuk dan (c) adalah 4. Sedangkan untuk aktivitas (b) yang berada pada range $>60^{\circ}(+1)$, maka skor untuk aktivitas (b) adalah 5 .

\section{Step 3, Posisi Kaki}

Pergerakan kaki saat beraktivitas dibedakan menjadi dua yaitu kaki yang tertopang sehingga bobot tersebar merata pada kedua kaki dan kaki yang tidak tertopang atau bobot beban yang tersebar tidak merata. Pemberian skor untuk pergerakan kaki dengan membandingkan foto postur teknisi $(a, b, c)$ dengan klasifikasi pergerakan kaki.

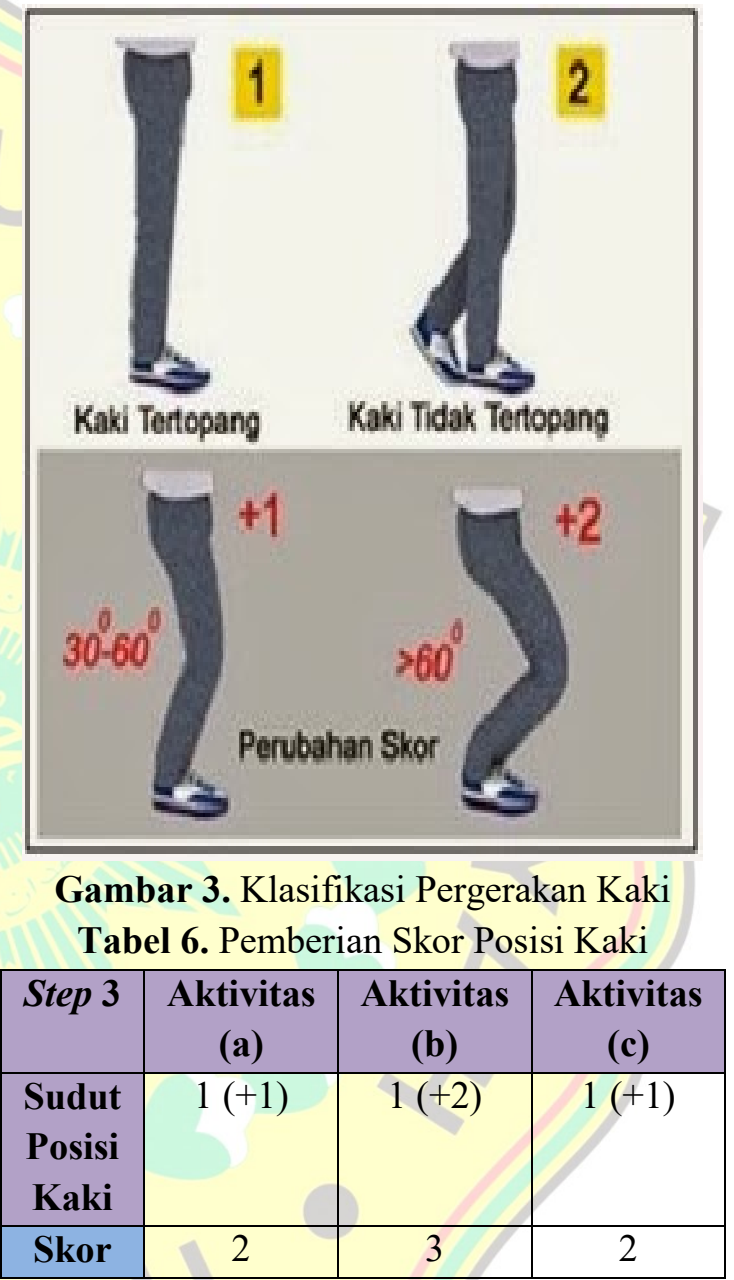

Dapat dilihat bahwa posisi pergerakan kaki aktivitas (a) teknisi tertopang dan kaki berada pada range sudut $0^{\circ}$ sehingga skor untuk aktivitas ini adalah 2. Pada aktivitas (b) teknisi tertopang dan kaki berada pada range sudut $>60^{\circ}$ sehingga skor untuk aktivitas ini adalah 3 . Sedangkan aktivitas (c) teknisi tertopang dan kaki berada pada range sudut $30^{\circ}-60^{\circ}$ sehingga skor untuk aktivitas ini adalah 2 .

\section{Step 4, Pengisian Tabel A}

Berikut merupakan klasifikasi Tabel A yang nantinya akan diisi oleh skor dari ketiga aktivitas di atas. 
Tabel 7. Tabel A REBA

\begin{tabular}{|c|c|c|c|c|c|c|c|c|c|c|c|c|c|}
\hline \multirow{2}{*}{ Table A } & \multicolumn{13}{|c|}{ Neck } \\
\hline & & \multicolumn{4}{|c|}{1} & \multicolumn{4}{|c|}{2} & \multicolumn{4}{|c|}{3} \\
\hline & & & & & & & & & & & & & \\
\hline & Legs & 1 & 2 & 3 & 4 & 1 & 2 & 3 & 4 & 1 & 2 & & 4 \\
\hline \multirow{5}{*}{$\begin{array}{c}\text { Trunk } \\
\text { Posture } \\
\text { Score }\end{array}$} & 1 & 1 & 2 & 3 & 4 & 1 & 2 & 3 & 4 & 3 & 3 & 5 & 6 \\
\hline & 2 & 2 & 3 & 4 & 5 & 3 & 4 & 5 & 6 & 4 & \begin{tabular}{|l|l}
5 \\
\end{tabular} & \begin{tabular}{l|l}
6 & \\
\end{tabular} & 7 \\
\hline & 3 & 2 & 4 & 5 & 6 & 4 & 5 & 6 & 7 & 5 & 6 & \begin{tabular}{l|l}
7 \\
\end{tabular} & 8 \\
\hline & 4 & 3 & 5 & 6 & 7 & 5 & 6 & 7 & 8 & 6 & 7 & 8 & 9 \\
\hline & 5 & 4 & 6 & 7 & 8 & 6 & 7 & 8 & 9 & 7 & \begin{tabular}{|l|}
8 \\
\end{tabular} & 9 & 9 \\
\hline
\end{tabular}

Tabel A berisi skor yang diperoleh dari posisi leher, punggung dan kaki sehingga didapatkan skor untuk tabel $\mathrm{A}$ adalah sebagai berikut.

Tabel 8. Pemberian Skor Tabel A

\begin{tabular}{|l|c|c|c|}
\hline Step 4 & $\begin{array}{c}\text { Aktivitas } \\
\text { (a) }\end{array}$ & $\begin{array}{c}\text { Aktivitas } \\
\text { (b) }\end{array}$ & $\begin{array}{c}\text { Aktivitas } \\
\text { (c) }\end{array}$ \\
\hline $\begin{array}{l}\text { Tabel } \\
\text { A }\end{array}$ & $(2,4,2)$ & $(2,5,3)$ & $(1,4,2)$ \\
\hline Skor & 6 & 8 & 5 \\
\hline
\end{tabular}

5. Step 5, Beban yang Diangkat

Foto postur tubuh teknisi pada ketiga gambar tersebut adalah saat memakai alat bantu seperti Spraygun, Block dan Kape.

Tabel 9. Klasifikasi Skor Beban

\begin{tabular}{|c|c|c|c|}
\hline \multicolumn{4}{|c|}{ Beban } \\
\hline 0 & 1 & 2 & +1 \\
\hline$<5$ & $5-10$ & $>10$ & $\begin{array}{c}\text { Penambahan beban } \\
\text { secara tiba-tiba atau } \\
\text { secara cepat. }\end{array}$ \\
$\mathrm{kg}$ & $\mathrm{kg}$ & $\mathrm{kg}$ & \begin{tabular}{c} 
Tecal \\
\hline
\end{tabular}
\end{tabular}

Karena beban yang diangkat pada ketiga aktivitas berada pada $<5 \mathrm{~kg}$ dan tidak terdapat penambahan beban secara tiba-tiba atau secara cepat, maka ketiga aktivitas pada Step ini skornya adalah 0 .

6. Step 6, Penambahan Skor Step 4 dan Step 5

Skor yang diperoleh pada Step 4 atau pada Tabel A akan ditambahkan dengan skor pada Step 5 untuk beban yang diangkat.

Tabel 10. Pemberian Skor Step 6

\begin{tabular}{|l|c|c|c|}
\hline Step 6 & $\begin{array}{c}\text { Aktivitas } \\
\text { (a) }\end{array}$ & $\begin{array}{c}\text { Aktivitas } \\
\text { (b) }\end{array}$ & $\begin{array}{c}\text { Aktivitas } \\
\text { (c) }\end{array}$ \\
\hline $\begin{array}{l}\text { Step 4 } \\
\text { + Step } \\
\text { 5 }\end{array}$ & $6+0$ & $8+0$ & $5+0$ \\
\hline
\end{tabular}

\begin{tabular}{|l|l|l|l|}
\hline Skor & 6 & 8 & 5 \\
\hline
\end{tabular}

B. Analisa Bagian Lengan Dan Pergelangan Tangan

1. Step 7, Posisi Lengan Atas

Pemberian skor untuk posisi lengan atas adalah dengan membandingkan foto postur teknisi (a, b, c) dengan gambar range pergerakan lengan atas.

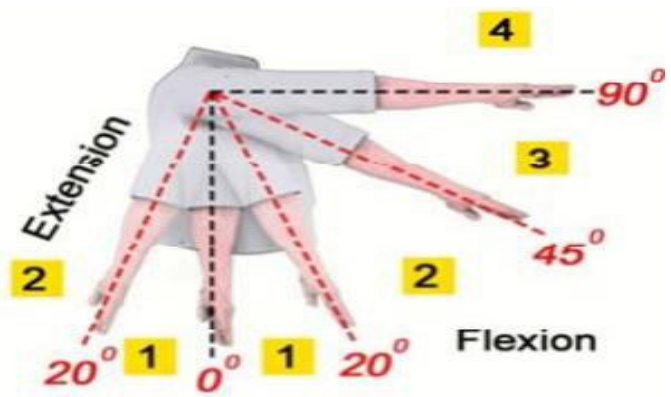

Gambar 4. Range Pergerakan Lengan Atas

Klasifikasi skor posisi lengan atas sesuai dengan ketentuan berikut:

Tabel 11. Klasifikasi Skor Posisi Lengan Atas

\begin{tabular}{|c|c|c|}
\hline $\begin{array}{c}\text { Posisi } \\
\text { Lengan Atas }\end{array}$ & Skor & $\begin{array}{l}\text { Perubahan } \\
\text { Skor }\end{array}$ \\
\hline $\begin{array}{l}20^{\circ} \text { extension } \\
\text { sampai } 20^{\circ} \\
\text { flexion }\end{array}$ & 1 & $\begin{array}{l}\text { +1 Jika posisi } \\
\text { lengan: } \\
\text { - }\end{array}$ \\
\hline $\begin{array}{l}>20^{\circ} \\
\text { extension }\end{array}$ & 2 & $\begin{array}{l}\text { Abducted } \\
-\quad \text { - Rotated }\end{array}$ \\
\hline $\begin{array}{l}20^{\circ}-45^{\circ} \\
\text { flexion }\end{array}$ & 2 & $\begin{array}{l}+1 \text { Jika bahu } \\
\text { ditinggikan }\end{array}$ \\
\hline $\begin{array}{l}45^{\circ}-90^{\circ} \\
\text { flexion }\end{array}$ & 3 & $\begin{array}{l}+1 \text { jika } \\
\text { besandar, bobot }\end{array}$ \\
\hline$>90^{\circ}$ flex & 4 & $\begin{array}{l}\text { lengan ditopang } \\
\text { atau sesuai } \\
\text { gravitasi }\end{array}$ \\
\hline
\end{tabular}

Tabel 12. Pemberian Skor Lengan Atas

\begin{tabular}{|l|c|c|c|}
\hline Step 7 & $\begin{array}{c}\text { Aktivitas } \\
\text { (a) }\end{array}$ & $\begin{array}{c}\text { Aktivitas } \\
\text { (b) }\end{array}$ & $\begin{array}{c}\text { Aktivitas } \\
\text { (c) }\end{array}$ \\
\hline $\begin{array}{l}\text { Sudut } \\
\text { Lengan } \\
\text { Atas }\end{array}$ & $45^{\circ}-90^{\circ}$ & $\begin{array}{c}45^{\circ}-90^{\circ} \\
(+1)\end{array}$ & $20^{\circ}-45^{\circ}$ \\
\hline Skor & 3 & 4 & 2 \\
\hline
\end{tabular}


Dapat dilihat posisi lengan atas teknisi pada aktivitas (a) berada pada range $45^{\circ}-90^{\circ}$ terhadap pusat tubuh, maka skor untuk aktivitas ini adalah 3. Sedangkan untuk aktivitas (b) berada pada range $45^{\circ}-90^{\circ}$ dan terlihat bahwa bahu sedikit ditinggikan untuk menyesuaikan posisi permukaan yang ingin diamplas, sehingga skor ditambahkan 1. Sehingga skor untuk aktivitas (b) adalah 4. Dan aktivitas (c) berada pada range $20^{\circ}-45^{\circ}$ terhadap pusat tubuh, maka skor untuk aktivitas ini adalah 2.

\section{Step 8, Posisi Lengan Bawah}

Pemberian skor untuk posisi lengan atas adalah dengan membandingkan foto postur teknisi (a, b, c) dengan gambar range pergerakan lengan bawah.

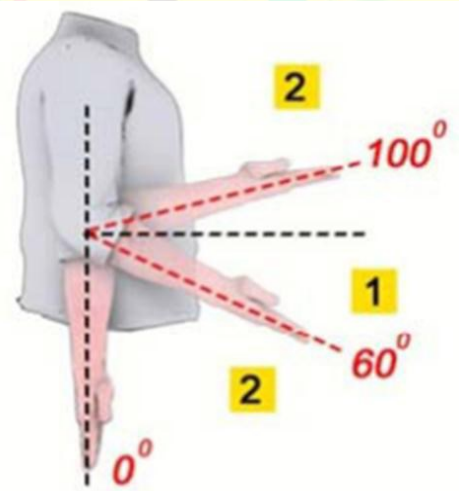

Gambar 4. Range Pergerakan Lengan Bawah

Klasifikasi skor posisi lengan bawah sesuai dengan ketentuan berikut:

Tabel 13. Klasifikasi Skor Posisi Lengan Bawah

\begin{tabular}{|l|c|}
\hline \multicolumn{1}{|c|}{ Posisi Lengan Bawah } & Skor \\
\hline $60^{\circ}-100^{\circ}$ flexion & 1 \\
\hline$<20^{\circ}$ flexion atau $>100^{\circ}$ flexion & 2 \\
\hline
\end{tabular}

Tabel 14. Pemberian Skor Posisi Lengan Bawah

\begin{tabular}{|l|c|c|c|}
\hline Step 8 & $\begin{array}{c}\text { Aktivitas } \\
\text { (a) }\end{array}$ & $\begin{array}{c}\text { Aktivitas } \\
\text { (b) }\end{array}$ & $\begin{array}{c}\text { Aktivitas } \\
\text { (c) }\end{array}$ \\
\hline $\begin{array}{l}\text { Sudut } \\
\text { Lengan } \\
\text { Bawah }\end{array}$ & $>100^{\circ}$ & $>100^{\circ}$ & $>100^{\circ}$ \\
\hline Skor & 2 & 2 & 2 \\
\hline
\end{tabular}

Dapat dilihat bahwa posisi lengan bawah teknisi pada ketiga aktivitas berada pada range sudut $>100^{\circ}$. Sehingga skor untuk posisi lengan bawah teknisi adalah 2 .

\section{Step 9. Posisi Pergelangan Tangan}

Pemberian skor untuk posisi pergelangan tangan adalah dengan membandingkan foto postur pergelangan tangan teknisi $(\mathrm{a}, \mathrm{b}, \mathrm{c})$ dengan gambar range pergerakan pergelangan tangan di bawah.

Klasifikasi skor posisi pergelangan tangan sesuai dengan ketentuan berikut:

Tabel 15. Klasifikasi Skor Posisi Pergelangan Tangan

\begin{tabular}{|l|c|l|}
\hline $\begin{array}{c}\text { Posisi } \\
\text { Pergelangan } \\
\text { Tangan }\end{array}$ & Skor & \multicolumn{1}{c|}{$\begin{array}{c}\text { Perubahan } \\
\text { Skor }\end{array}$} \\
\hline $\begin{array}{l}0^{\circ}-15^{\circ} \text { flexion/ } \\
\text { extension }\end{array}$ & 1 & $\begin{array}{l}+1 \text { Jika } \\
\text { pergelangan } \\
\text { tangan } \\
\text { menyimpang/ } \\
\text { berputar } \\
\text { extension }\end{array}$ \\
\hline
\end{tabular}

Tabel 16. Pemberian Skor Posisi Pergelangan Tangan

\begin{tabular}{|l|l|l|l|}
\hline Step 9 & $\begin{array}{l}\text { Aktivit } \\
\text { as (a) }\end{array}$ & $\begin{array}{l}\text { Aktivit } \\
\text { as (b) }\end{array}$ & $\begin{array}{l}\text { Aktivit } \\
\text { as (c) }\end{array}$ \\
\hline $\begin{array}{l}\text { Sudut } \\
\text { Pergelang } \\
\text { an Tangan }\end{array}$ & $0^{\circ}-15^{\circ}$ & $\begin{array}{l}0^{\circ}-15^{\circ} \\
(+1)\end{array}$ & $\begin{array}{l}15^{\circ} \\
\text { flexion }\end{array}$ \\
\hline Skor & 1 & 2 & 2 \\
\hline
\end{tabular}

Skor untuk posisi pergelangan tangan aktivitas (b) dan (c) berada pada range $0^{\circ}-15^{\circ}$ $(+1)$ dan $15^{\circ}$ flexion, maka skor untuk kedua aktivitas ini adalah 2. Sedangkan skor untuk aktivitas (a) adalah 1.

4. Step 10, Pengisian Tabel B

Berikut merupakan klasifikasi Tabel A yang nantinya akan diisi oleh skor dari ketiga aktivitas di atas. 
Tabel 17. Tabel B REBA

\begin{tabular}{|c|c|c|c|c|c|c|c|}
\hline \multirow{2}{*}{$\begin{array}{c}\text { Table } \\
B\end{array}$} & \multicolumn{6}{|c|}{ Lower Arm } \\
\cline { 2 - 8 } & & \multicolumn{3}{|c|}{1} & \multicolumn{2}{|c|}{2} \\
\hline \multirow{4}{*}{} & \multirow{2}{*}{ Wrist } & \multicolumn{7}{|c|}{} & \multicolumn{3}{|c|}{} \\
\cline { 2 - 8 } & 1 & 2 & 3 & 1 & 2 & 3 \\
\hline \multirow{4}{*}{$\begin{array}{c}\text { Uppery } \\
\text { Arm }\end{array}$} & 1 & 1 & 2 & 2 & 1 & 2 & 3 \\
\cline { 2 - 8 } & 2 & 1 & 2 & 3 & 2 & 3 & 4 \\
\cline { 2 - 8 } & 3 & 3 & 4 & 5 & 4 & 5 & 5 \\
\cline { 2 - 8 } & 4 & 4 & 5 & 5 & 5 & 6 & 7 \\
\cline { 2 - 8 } & 5 & 6 & 7 & 8 & 7 & 8 & 8 \\
\cline { 2 - 8 } & 6 & 7 & 8 & 8 & 8 & 9 & 9 \\
\hline
\end{tabular}

Tabel B berisi skor yang diperoleh dari posisi lengan atas, lengan bawah dan pergelangan tangan sehingga didapatkan skor sebagai berikut.

Tabel 18. Pemberian Skor Tabel B

\begin{tabular}{|l|c|c|c|}
\hline Step 10 & $\begin{array}{c}\text { Aktivitas } \\
\text { (a) }\end{array}$ & $\begin{array}{c}\text { Aktivitas } \\
\text { (b) }\end{array}$ & $\begin{array}{c}\text { Aktivitas } \\
\text { (c) }\end{array}$ \\
\hline Tabel B & $(3,2,1)$ & $(4,2,2)$ & $(2,2,2)$ \\
\hline Skor & 4 & 6 & 3 \\
\hline
\end{tabular}

5. Step 11, Penilaian Coupling

Berikut ini merupakan syarat-syarat coupling pada tabel REBA. Nilai untuk teknisi saat membawa/ mengambil benda adalah Unacceptable.

Tabel 19. Penilaian Coupling

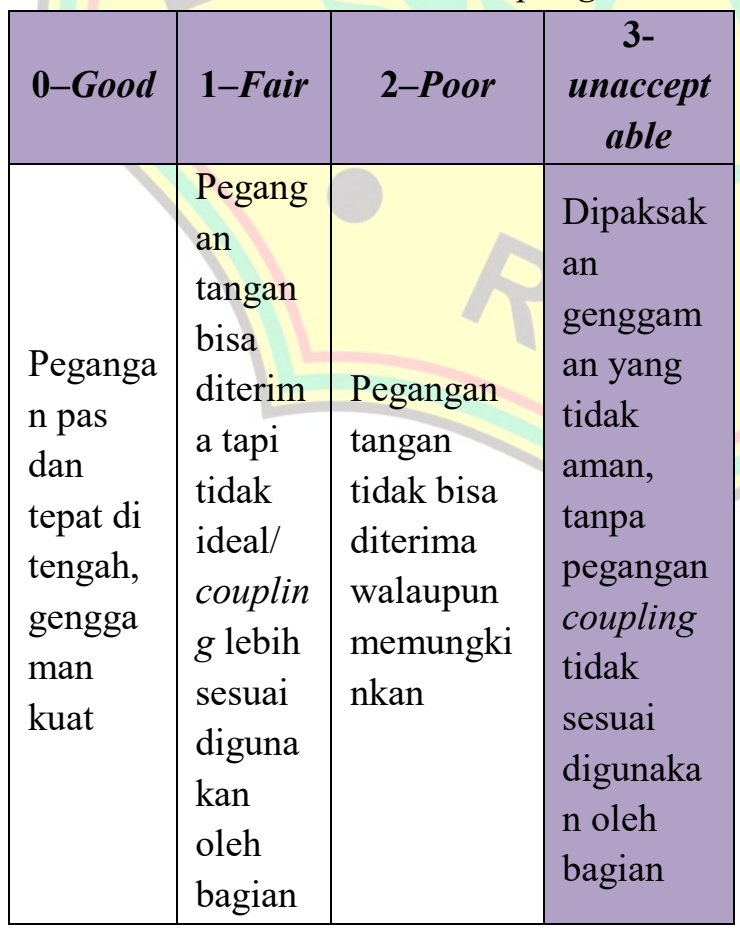

\begin{tabular}{|l|l|l|l|}
\hline $\begin{array}{l}\text { lain } \\
\text { dari } \\
\text { tubuh }\end{array}$ & & $\begin{array}{l}\text { lain dari } \\
\text { tubuh }\end{array}$ \\
\hline
\end{tabular}

Aktivitas a adalah seorang teknisi sedang memegang spraygun, skor coupling aktivitas a adalah 0. Aktivitas $\mathrm{b}$ adalah teknisi sedang melakukan pengamplasan, skor coupling aktivitas b adalah 0. Sedangkan Aktivitas c adalah teknisi sedang melakukan pendempulan , skor coupling aktivitas $\mathrm{c}$ adalah 0 .

6. Step 12, Pengisian Tabel C

Berikut merupakan klasifikasi Tabel $\mathrm{C}$ yang nantinya akan diisi oleh hasil skor Tabel A dan Tabel B di atas.

Tabel 20. Tabel C REBA

\begin{tabular}{|c|c|c|c|c|c|c|c|c|c|c|c|c|}
\hline \multirow{2}{*}{$\begin{array}{c}\text { Score } A \\
\text { (score from } \\
\text { table } A \\
\text { +load/force } \\
\text { score) }\end{array}$} & \multicolumn{10}{|c|}{ Sable C } \\
\cline { 2 - 13 } & 1 & 2 & 3 & 4 & 5 & 6 & 7 & 8 & 9 & 10 & 11 & 12 \\
\hline 1 & 1 & 1 & 1 & 2 & 3 & 3 & 4 & 5 & 6 & 7 & 7 & 7 \\
\hline 2 & 1 & 2 & 2 & 3 & 4 & 4 & 5 & 6 & 6 & 7 & 7 & 8 \\
\hline 3 & 2 & 3 & 3 & 3 & 4 & 5 & 6 & 7 & 7 & 8 & 8 & 8 \\
\hline 4 & 3 & 4 & 4 & 4 & 5 & 6 & 7 & 8 & 8 & 9 & 9 & 9 \\
\hline 5 & 4 & 4 & 4 & 5 & 6 & 7 & 8 & 8 & 9 & 9 & 9 & 9 \\
\hline 6 & 6 & 6 & 6 & 7 & 8 & 8 & 9 & 9 & 10 & 10 & 10 & 10 \\
\hline 7 & 7 & 7 & 7 & 8 & 9 & 9 & 9 & 10 & 10 & 11 & 11 & 11 \\
\hline 8 & 8 & 8 & 8 & 9 & 10 & 10 & 10 & 10 & 10 & 11 & 11 & 11 \\
\hline 9 & 9 & 9 & 9 & 10 & 10 & 10 & 11 & 11 & 11 & 12 & 12 & 12 \\
\hline 10 & 10 & 10 & 10 & 11 & 11 & 11 & 11 & 12 & 12 & 12 & 12 & 12 \\
\hline 11 & 11 & 11 & 11 & 11 & 12 & 12 & 12 & 12 & 12 & 12 & 12 & 12 \\
\hline 12 & 12 & 12 & 12 & 12 & 12 & 12 & 12 & 12 & 12 & 12 & 12 & 12 \\
\hline
\end{tabular}

Pengisian tabel $\mathrm{C}$ diperoleh dari skor pada Tabel A dan (Tabel B + Penilaian Coupling), sehingga diperoleh skor untuk Tabel $\mathrm{C}$ adalah sebagai berikut.

Tabel 21. Pemberian Skor Tabel C

\begin{tabular}{|l|l|l|l|}
\hline $\begin{array}{l}\text { Step } \\
\mathbf{1 2}\end{array}$ & $\begin{array}{l}\text { Aktivitas } \\
\text { (a) }\end{array}$ & $\begin{array}{l}\text { Aktivitas } \\
\text { (b) }\end{array}$ & $\begin{array}{l}\text { Aktivitas } \\
\text { (c) }\end{array}$ \\
\hline $\begin{array}{l}\text { Tabel } \\
\text { C }\end{array}$ & $(6,4)$ & $(8,6)$ & $(5,3)$ \\
\hline Skor & 7 & 10 & 4 \\
\hline
\end{tabular}


7. Step 13, Activity Score

Setelah diperoleh skor pada Tabel C, langkah selanjutnya adalah menambahkan skor pada Tabel C dengan skor pada Activity Score. Berdasarkan ketiga aktivitas yang dilakukan teknisi, skor akan ditambah 1 karena aktivitas tersebut menyebabkan perubahan atau pergeseran postur yang cepat dari posisi awal.

Tabel 22. Klasifikasi Activity Score

\begin{tabular}{|l|l|l|}
\hline \multicolumn{3}{|c|}{ Activity Score } \\
\hline & +1 Jika & +1 Jika \\
+1 Jika 1 & pengulangan & gerakan \\
atau lebih & gerakan dalam & menyebabkan \\
bagian & rentang waktu & perubahan \\
tubuh & singkat, & atau \\
statis, & diulang lebih & pergeseran \\
ditahan & dari 4 kali per & postur yang \\
lebih dari 1 & menit (tidak & cepat dari \\
menit & termasuk & posisi awal \\
& berjalan) & \\
\hline
\end{tabular}

Tabel 23. Pemberian Skor Aktivitas

\begin{tabular}{|c|c|c|c|}
\hline Step 13 & $\begin{array}{c}\text { Aktivitas } \\
\text { (a) }\end{array}$ & $\begin{array}{c}\text { Aktivitas } \\
\text { (b) }\end{array}$ & $\begin{array}{c}\text { Aktivitas } \\
\text { (c) }\end{array}$ \\
\hline $\begin{array}{c}\text { Skor } \\
\text { Aktivitas }\end{array}$ & $(7+1)$ & $(10+1)$ & $(4+1)$ \\
\hline Skor & 8 & 11 & 5 \\
\hline
\end{tabular}

Setelah mendapatkan skor akhir, maka langkah selanjutnya adalah menentukan aktivitas tersebut termasuk dalam kategori sesuai dengan tabel resiko sebagai berikut.

Tabel 24. Tabel Resiko Ergonomi Metode REBA

\begin{tabular}{|c|c|l|}
\hline $\begin{array}{c}\text { Skor } \\
\text { REBA }\end{array}$ & $\begin{array}{c}\text { Risk } \\
\text { Level }\end{array}$ & \multicolumn{1}{|c|}{ Tindakan } \\
\hline 1 & Diabaikan & Tidak Diperlukan \\
\hline $2-3$ & Low & $\begin{array}{l}\text { Mungkin } \\
\text { Diperlukan }\end{array}$ \\
\hline $4-7$ & Medium & Diperlukan \\
\hline $8-10$ & High & $\begin{array}{l}\text { Segera } \\
\text { Diperlukan }\end{array}$ \\
\hline $11-15$ & Very High & $\begin{array}{l}\text { Diperlukan } \\
\text { Sekarang }\end{array}$ \\
\hline
\end{tabular}

Berikut merupakan rekapitulasi hasil penilaian REBA dari ketiga aktivitas $(a, b, c)$ di atas.

Tabel 25. Hasil Pengolahan REBA

\begin{tabular}{|c|c|c|c|c|c|c|}
\hline \multirow{2}{*}{ 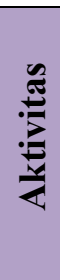 } & \multicolumn{6}{|c|}{$\begin{array}{c}\text { Rapid Entire Body Assesment } \\
\text { (REBA) }\end{array}$} \\
\hline & 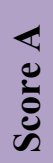 & 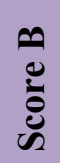 & $\begin{array}{l}0 \\
0 \\
\ddot{\Xi}\end{array}$ & 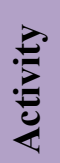 & 焉 & 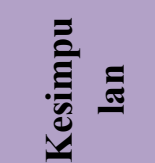 \\
\hline (a) & 6 & 4 & 7 & 1 & 8 & high risk \\
\hline (b) & 8 & 6 & 10 & 1 & 11 & $\begin{array}{l}\text { very high } \\
\text { risk }\end{array}$ \\
\hline (c) & 5 & 3 & 4 & 1 & 5 & $\begin{array}{l}\text { medium } \\
\text { risk }\end{array}$ \\
\hline
\end{tabular}

Hasil penilaian postur kerja teknisi dengan REBA untuk aktivitas (a) adalah termasuk kategori high risk yang berarti diperlukan tindakan perbaikan segera. Adapun high risk pada aktivitas ini dipengaruhi oleh posisi punggung yang memiliki skor 4 dan juga posisi lengan atas yang tidak ergonomis. Hasil penilaian postur kerja teknisi dengan REBA untuk aktivitas (b) adalah termasuk kategori very high risk yang berarti diperlukan tindakan perbaikan sekarang. Adapun high risk pada aktivitas ini dipengaruhi oleh posisi punggung yang memiliki skor 5, posisi lengan atas,dan pergerakan lengan yang tidak ergonomis. Jadi, perlu ada perbaikan sekarang pada posisi posisi punggung dan pergerakan lengan. Sedangkan untuk aktivitas (c) termasuk dalam kategori medium risk yang berarti diperlukan perbaikan pada postur ini. Postur kerja yang kurang baik tersebut dilakukan dalam intensitas yang cukup tinggi dalam satu hari. Jika hal ini dibiarkan saja secara terus menerus, maka potensi resiko teknisi menderita cedera tulang belakang dan cedera pada bagian punggung dan lengan akan semakin tinggi.

Berdasarkan hasil penilaian ergonomi dengan cara analisa postur kerja, hasilnya berada pada kondisi yang tidak ergonomis. Terbukti bahwa indikasi tempat kerja atau posisi kerja yang tidak ergonomis adalah ketika teknisi mengeluhkan adanya nyeri atau sakit 
pada leher, bahu, punggung atau pinggang, postur kerja yang buruk yaitu sering membungkuk dan lain sebagainya. Oleh karena itu perlu adanya rekomendasi perbaikan untuk bagian painting di PT. Jakarta Teknologi Utama Motor Pekanbaru. Perbaikan atau pengendalian terkait ergonomi meliputi:.

A. Pengendalian pada teknisi

Aktivitas (a) : Pengecatan

1. Mengubah posisi kerja. Agar meminimalisir resiko terjadi cedera tulang belakang akibat terlalu sering membungkuk, teknisi harus mengubah posisi kerja yang lebih nyaman dengan lebih banyak bertumpu pada gerakan bagian bawah tubuh atau kaki untuk menjangkau bagian bawah bodi kendaraan . Hal ini dapat mengubah posisi punggung menjadi lebih netral.

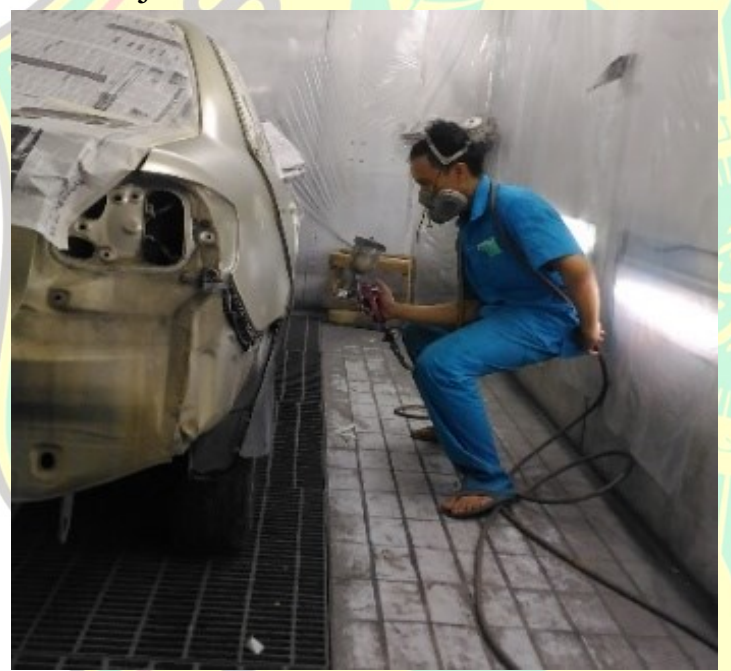

Gambar 6. Posisi Kerja yang

Direkomendasikan

2. Menambahkan bangku pijakan saat pengaplikasian pengecatan di bagian bodi kendaraan yang tinggi atau sulit dijangkau.

3. Menggunakan seragam kerja (wear pack) yang berbahan menyerap keringat sebab teknisi selalu berkeringat lebih saat melakukan pekerjaan di ruangan Spraybooth dikarenakan intensitas kerja yang tinggi dan juga suhu ruangan yang panas.

4. Menggunakan alat safety yang disediakan seperti masker wajah, kacamata, sarung tangan anti solvent, dll.
Aktivitas (b): Pendempulan

1. Menggunakan alat bantu berupa stand atau dudukan. Pada saat teknisi melakukan aktivitas pendempulan, apabila sedang memperbaiki part-part kendaraan yang terpisah ada baiknya menggunakan alat bantu berupa stand atau dudukan. Manajemen perlu banyak menyediakan alat ini untuk memudahkan pekerjaan teknisi. Alat tersebut bisa seperti gambar di bawah ini:

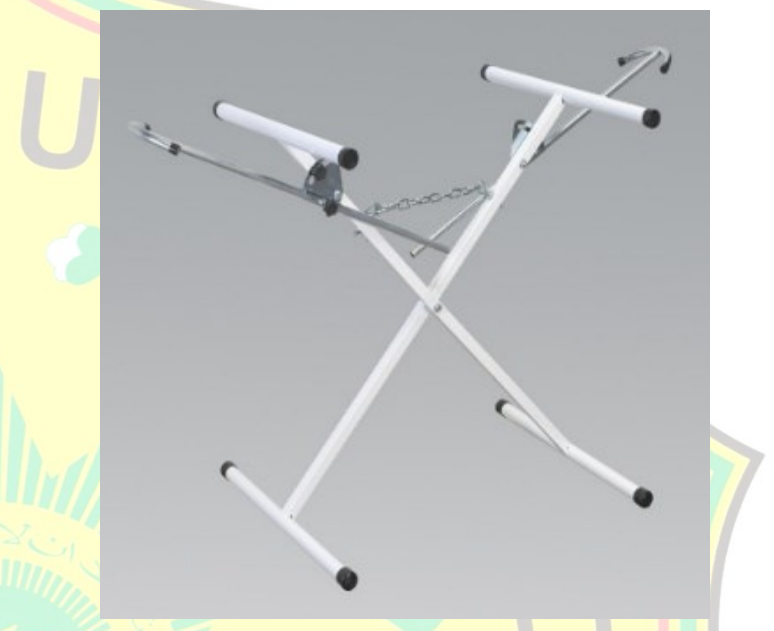

Gambar 7. Stand untuk Part Lepasan

Adapun manfaat alat tersebut adalah sebagai dudukan part lepasan sehingga teknisi bisa menyesuaikan posisi part dengan postur tubuh sehingga teknisi tidak perlu terlalu membungkuk dalam bekerja.

2. Menambahkan bangku pijakan saat pengaplikasian pendempulan di bagian bodi kendaraan yang tinggi atau sulit dijangkau. Untuk pengerjaan bagian bawah, teknisi bisa menyesuaikan posisi yang nyaman agar tidak terlalu memaksakan punggung untuk membungkuk misalnya duduk atau jongkok.

3. Menggunakan alat safety yang digunakan seperti masker wajah dan sarung tangan.

\section{Aktivitas (c) : Pengamplasan}

1. Menggunakan Dry Sanding, Saat teknisi melakukan aktivitas pengamplasan atau sanding, yang biasanya masih rutin menggunakan amplas basah dengan bantuan air (wet sanding) sebaiknya 
beralih menggunakan amplas kering (dry sanding) secara menyeluruh. Selain berfungsi untuk mengurangi tenaga yang harus dikeluarkan saat melakukan pengamplasan, dry sanding juga lebih mempercepat penyelesaian pekerjaan karena dipadukan dengan alat bantu berupa Sander. Alat tersebut bisa seperti gambar dibawah ini:

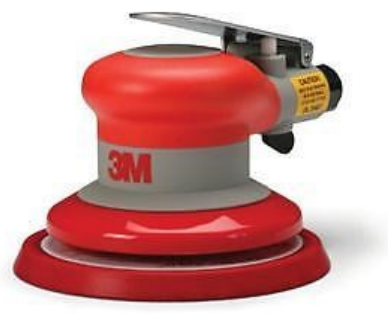

Gambar 8. Contoh Alat Bantu Dry Sanding

Adapun sistem kerja alat tersebut adalah dengan berputar dibantu oleh tenaga angin (pneumatic) dari kompresor sehingga teknisi hanya perlu menempatkan alat tersebut pada permukaan yang ingin diratakan atau dihaluskan tanpa perlu melakukan gerakan tangan berulang dan mengeluarkan tenaga lebih dikarenakan alat tersebut berputar otomatis meratakan dan menghaluskan permukaan panel kendaraan. Teknisi juga bisa menyesuaikan posisi kerja yang dirasa aman dan nyaman sebab alat ini hanya perlu di tempelkan pada permukaan panel kendaraan. Berikut ini gambar contoh penggunaan alat sander tersebut:

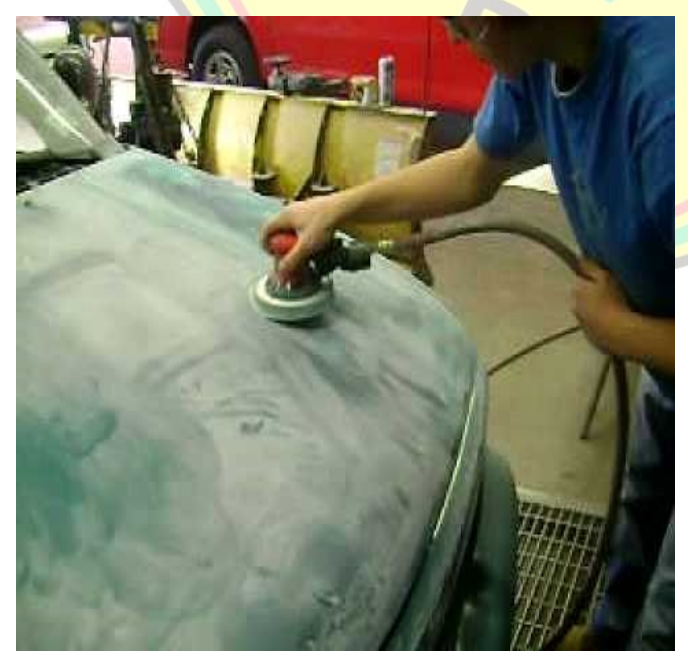

Gambar 10. Contoh Penggunaan Sander
2. Mengurutkan penggunaan grid amplas dari yang paling kasar hingga yang paling halus saat melakukan pengamplasan, hal ini dapat mempercepat proses pengerjaan dan memperoleh hasil permukaan yang baik dan halus.

3. Menggunakan alat pelindung seperti masker wajah dan sarung tangan.

B. Pengendalian administratif

Pengendalian administratif yang dapat dilakukan oleh manajemen PT. Jakarta Teknologi Utama Motor Pekanbaru adalah dengan :

1. Mempertegas aturan kerja atau Standard Operational Prosedur (SOP) sesuai dengan aturan yang sebenarnya, sebab dalam prakteknya SOP pada bagian produksi ini sering kali diabaikan oleh para teknisi. SOP yang benar berguna untuk menekan keluhan MSDs dan menghindari postur kerja yang tidak nyaman dan tidak aman.

2. Penjadwalan waktu istirahat sebanyak 5 menit tiap jam juga dibutuhkan untuk memberikan kesempatan teknisi melepas lelah.

3. Selain itu, manajemen hendaknya peduli dengan kesehatan teknisi dengan memberikan jaminan kesehatan dan keselamatan kerja.

\section{KESIMPULAN}

Dari penelitian yang dilakukan maka dapat ditarik beberapa kesimpulan sebagai berikut :

a. Berdasarkan rekapitulasi hasil pengolahan data jenis keluhan dengan Nordic Body Map, diketahui bahwa rata-rata jenis keluhan bernilai 3 (Sakit) pada bagian tubuh nomor 1, 3, 5, 7, 8 dan 15 yang berarti seluruh teknisi merasakan sakit pada bagian leher bawah, bahu kanan, punggung, pinggang, pinggul dan pergelangan tangan kanan. Selain itu terdapat 14 bagian tubuh lainnya yang dirasa agak sakit oleh teknisi. 
b. Hasil penilaian postur kerja teknisi dengan REBA untuk aktivitas (a) adalah termasuk kategori high risk yang berarti diperlukan tindakan perbaikan segera. Untuk aktivitas (b) adalah termasuk kategori very high risk yang berarti diperlukan tindakan perbaikan sekarang. Sedangkan untuk aktivitas (c) termasuk dalam kategori medium risk yang berarti diperlukan perbaikan pada postur ini. Postur kerja yang tidak ergonomis tersebut dilakukan dalam intensitas yang cukup tinggi dalam satu hari. Jika hal ini dibiarkan saja secara terus menerus, maka potensi resiko teknisi menderita cedera tulang belakang dan cedera pada bagian punggung dan lengan akan semakin tinggi.

c. Rekomendasi yang diberikan agar dapat mengurangi resiko cedera pada teknisi yaitu perlu ada perbaikan posisi kerja dan peralatan kerja. Untuk Aktivitas (a) perlu mengubah posisi kerja yang lebih nyaman dan ergonomis dengan lebih banyak bertumpu pada bagian bawah tubuh untuk menjangkau bagian bawah bodi kendaraan serta penggunaan bangku pijakan untuk menjangkau bagian yang tinggi. Untuk aktivitas (b) perlu penambahan alat bantu berupa stand atau dudukkan. Teknisi bisa menyesuaikan posisi part dengan postur tubuh sehingga teknisi tidak perlu terlalu membungkuk dalam bekerja. Untuk aktivitas (c) perlu penggunaan dry sanding disertai alat bantu berupa sander. Selain berfungsi untuk mengurangi tenaga yang harus dikeluarkan saat melakukan pengamplasan, dry sanding juga lebih mempercepat penyelesaian pekerjaan.

\section{DAFTAR PUSTAKA}

A Step-by-Step guide to REBA. Diakses di : www.ergo-plus.com (26 Mei 2016)

Andika, M. 2013. REBA (Rapid Entire body Assessment). Kumpulan Skripsi. Universitas Sumatera Utara. Medan. Diakses dari: http://repository.usu.ac.id (26 Mei 2016)

Ari Fatmawati. 2011. Analisa postur kerja dengan menggunakan metode rapid entire body assessment (REBA). Universitas Muhammadiyah Surakarta. Diambil dari:

http://eprints.ums.ac.id/551 (2 Juni 2016)

Bab 2 Landasan teori. Nordic body map. Diambil dari:

http://elib.unikom.ac.id/ (20 Mei 2016)

Merulalia. 2010. Pengertian Muscoluskeletal Disorders (MSDs). Di ambil dari: http://merulalia.wordpress.com (26 Mei 2016)

http://ergonomi-teknikindustri.blogspot.com (26 Mei 2016) 